Canadian

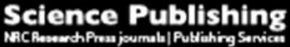

Canadian Journal of Zoology Revue canadienne de zoologie

\title{
Low-temperature tolerances of tropical fish with potential transgenic applications in relation to winter water temperatures in Canada
}

\begin{tabular}{|r|l|}
\hline Journal: & Canadian Journal of Zoology \\
\hline Manuscript ID & cjz-2017-0043.R1 \\
\hline Manuscript Type: & Article \\
\hline Date Submitted by the Author: & $13-J u l-2017$ \\
\hline Complete List of Authors: & $\begin{array}{l}\text { Leggatt, Rosalind; Department of Fisheries and Oceans, CAER } \\
\text { Dhillion, Rashpal; University of British Columbia, Zoology; University of } \\
\text { Wisconsin Madison, Wisconsin Institute for Discovery - Epigenetics } \\
\text { Mimeault, Caroline; Department of Fisheries and Oceans, Aquaculture, } \\
\text { Biotechnology and Aquatic Animal Health Branch } \\
\text { Johnson, Neville; Department of Fisheries and Oceans, Aquaculture, } \\
\text { Biotechnology and Aquatic Animal Health Branch } \\
\text { Richards, Jeffrey; University of British Columbia, Department of Zoology } \\
\text { Devlin, Robert; Fisheries and Oceans Canada, }\end{array}$ \\
\hline Keyword: & $\begin{array}{l}\text { ANIMAL IMPACT < Discipline, COLD HARDINESS < Discipline, GENETIC } \\
\text { ENGINEERING < Discipline, TEMPERATURE < Discipline, FRESHWATER < } \\
\text { Habitat, TEMPERATE < Habitat, FISH < Taxon }\end{array}$ \\
\hline
\end{tabular}


$23{ }^{1}$ Current affiliation: Department of Biomolecular Chemistry, Wisconsin Institute for Discovery - Epigenetics,

\section{Low-temperature tolerances of tropical fish with potential transgenic applications in} relation to winter water temperatures in Canada

\author{
R.A. Leggatt, R.S. Dhillon, C. Mimeault, N. Johnson, J.G. Richards, R.H. Devlin
}

Corresponding author: R.A. Leggatt: Centre for Aquaculture and the Environment, Centre for Biotechnology and Regulatory Research, Fisheries and Oceans Canada, 4160 Marine Drive, West Vancouver, BC, V7V 1N6, Canada, Email: rosalind.leggatt@dfo-mpo.gc.ca, Tel: +1-604-666-7909, Fax: +1-604-666-3474

R.S. Dhillon ${ }^{1}$ : Department of Zoology, University of British Columbia, 4200-6270 University Blvd. Vancouver, BC, V6T 1Z4, Canada, rdhillon2@wisc.edu

C. Mimeault: Aquaculture, Biotechnology and Aquatic Animal Health Branch, Fisheries and Oceans Canada, 200 Kent St, Ottawa, ON, K1A 0E6, Canada, Email: Caroline.Mimeault@dfo-mpo.gc.ca

N. Johnson: Aquaculture, Biotechnology and Aquatic Animal Health Branch, Fisheries and Oceans Canada, 200 Kent St, Ottawa, ON K1A 0E6, Canada, Email: Neville.Johnson@dfo-mpo.gc.ca

J.G. Richards: Department of Zoology, University of British Columbia, 4200-6270 University Blvd. Vancouver, BC, V6T 1Z4, Canada, Email: jrichard@zoology.ubc.ca

R.H. Devlin: Centre for Aquaculture and the Environment, Centre for Biotechnology and Regulatory Research, Fisheries and Oceans Canada, 4160 Marine Drive, West Vancouver, BC, V7V 1N6, Canada, Email: Robert.Devlin@dfo-mpo.gc.ca

24 University of Wisconsin, 330 N. Orchard St., Madison, WI, 53715, USA 
25 Low-temperature tolerances of tropical fish with potential transgenic applications in

26 relation to winter water temperatures in Canada

27 R.A. Leggatt, R.S. Dhillon, C. Mimeault, N. Johnson, J.G. Richards, R.H. Devlin

Abstract: Application of fluorescent protein transgenes in tropical freshwater fish is used in research (e.g. in zebrafish), and for the commercial ornamental aquarium trade. To assess the

31 overwinter potential of such fish in Canada, we examined the minimum temperature tolerance of

32 three wild-type species (zebrafish Danio rerio Hamilton, 1822; black tetra Gymnocorymbus

33 ternetzi Boulenger, 1895; tiger barb Puntius tetrazona Bleeker, 1855) used as fluorescent

34 models in the aquarium trade, and four lines of green fluorescent protein (GFP) transgenic and

35 wild-type zebrafish used in research. Both tetra and barb had lower temperature tolerance limits

36 that were higher than surveyed winter temperatures in Canada, and the lower tolerance limits of

37 zebrafish lines was only within the range of a few surveyed lakes in some years. One line of GFP

38 zebrafish had a lower temperature tolerance limit that was significantly higher than those of other

39 lines, suggesting some fluorescent transgene constructs may alter tolerance to extreme

40 temperatures. When lines of zebrafish were reared at 8,10 , or $28^{\circ} \mathrm{C}$ for four months all lines

41 were capable of producing viable embryos after cold rearing. These results indicate tropical

42 transgenic fish models used in research and the aquarium trade are not expected to persist

43 overwinter in Canadian water systems.

45 Keywords: Danio rerio; zebra danio; Gymnocorymbus ternetzi; white tetra; Puntigrus tetrazona;

46 tiger barb; thermal minimum; temperature; fluorescent protein; transgene; risk assessment;

47 survival; overwinter 


\section{Introduction}

51 Transgenic tropical fish containing fluorescent protein transgenes are commonly used in research

52 (e.g. zebrafish, Lin et al. 2016) and in the ornamental aquarium trade (e.g. GloFish ${ }^{2}$, USA).

53 Insertion of fluorescent protein transgenes can result in directed or universal expression of

54 exogenous fluorescent proteins in numerous organisms, including fish. Great advancements in

55 developmental biology and gene regulation have been undertaken using tropical-origin zebrafish

56 (Danio rerio Hamilton, 1822) models that have targeted fluorescent visualization of key proteins

57 (see Udvadia and Linney 2003; Lin et al. 2016). Use of fluorescent protein transgenes as a

58 reporter genes was first demonstrated in zebrafish in 1995 (Amsterdam et al. 1995), and has

59 expanded to use of multiple tags in a single fish such as tagging superficial epithelial cell

60 populations with dozens of distinguishable tags for quantitative in vivo imaging (Chen et al.

61 2016). In addition, ornamental tropical freshwater fish that have universal and/or muscle/skin-

62 specific expression of various fluorescent transgenes to produce stunning visual colours are

63 commercially available in some countries. For example, GloFish ${ }^{\circledR}$ (Yorktown Technologies,

64 Austin, Texas) in the USA are available in multiple fluorescent colours three species: wild-type

65 morph (i.e. striped) and golden morph of zebrafish (also known as golden zebra danios), the

66 white morph of black tetras (Gymnocorymbus ternetzi Boulenger, 1895, also known as white

67 tetras or white skirt tetras) and tiger barbs (Puntigrus tetrazona Bleeker, 1855). A transgenic red

68 fluorescent protein (RFP) zebrafish was the first approved and marketed strain in 2003 in the US

69 excluding California, followed by an updated RFP model and additional colour variants in

70 following years (Hill et al. 2011; Hill et al. 2014). A GFP transgenic tetra was introduced in 2012

71 followed by additional colour variants, and two colour variants of tiger barbs were introduced in 
722014 (Hill et al. 2014). Approval to sell GloFish ${ }^{\circledR}$ in California was granted in 2015 (California

73 Fish and Game Commission 2015). With increasing potential application of fluorescent

74 transgenic models in both research and the ornamental aquarium trade, information to

75 scientifically assess the potential for such fish to establish in natural water systems is needed to

76 inform risk assessment prior to their use to support decisions to protect Canadian environments.

77 The purpose of our study was to determine the potential for common tropical research fish, as

78 well as progenitor strains for commercial ornamental aquarium fish, to establish themselves in

79 Canadian waters.

81 In temperate regions such as much of the high population density areas in Canada, the ability for

82 transgenic tropical species such as zebrafish and other ornamentals to establish themselves is

83 primarily limited by their ability to overwinter in cold water bodies. For example, Cortemeglia

84 and colleagues (Cortemeglia and Beitinger 2005, 2006; Cortemeglia et al. 2008) examined the

85 cold temperature tolerance of wild-type zebrafish and the original RFP zebrafish used in the

86 ornamental aquarium trade, and contrasted it to potential survival distribution across the USA.

87 They found that chronic lethal minimum temperature $\left(\mathrm{CL}_{\min }\right.$, measured by gradual decreases in

88 temperature $)$ and critical thermal minimum temperature $\left(\mathrm{CT}_{\min }\right.$, measured by rapid linear decline

89 in temperature) were above $4^{\circ} \mathrm{C}$ for both $\mathrm{RFP}\left(5.6\right.$ and $7.2^{\circ} \mathrm{C}$ respectively) and an unrelated wild-

90 type zebrafish $\left(5.3\right.$ and $6.2^{\circ} \mathrm{C}$ respectively) when acclimated to $20^{\circ} \mathrm{C}$ (Cortemeglia and Beitinger

912005,2006 ), and confirmed neither group of fish were able to withstand four days at $4^{\circ} \mathrm{C}$ in a

92 field trial (Cortemeglia et al. 2008). Based on surface air temperature measurements, they

93 hypothesized that projected distribution of zebrafish lines in the USA would be limited to

94 isolated areas in the southern States (Cortemeglia and Beitinger 2006). While RFP zebrafish 
95 displayed less cold tolerance than control fish, it should be noted that the control fish were

96 obtained from a different source than RFP zebrafish, and whether the altered minimum thermal

97 tolerances of RFP fish were due differences in rearing conditions or possibly background

98 genetics is not known. As well, currently marketed transgenic zebrafish are available in both a

99 striped and golden morph of the zebrafish, and whether these morphs alter thermotolerance in

100 zebrafish has not been examined. In addition, whether transgenic inserts used in research may

101 also impact thermotolerance has not been examined. Hill et al. (2014) applied the Fish

102 Invasiveness Screening Kit (FISK) to all three species used as Glofish ${ }^{\circledR}$, and concluded a low-

103 risk of invasiveness within the USA based on no potential for hybridization for native species,

104 little history of invasiveness despite high potential for release, lack of traits associated with

105 invasiveness, small body size and predation-enhancing fluorescence. For scientifically defensible

106 risk assessment, experiments to determine overwinter capabilities are needed to confirm this lack

107 of potential to persist in Canadian waters, particularly in tetra and tiger barb where no published

108 scientific data on cold tolerance exists.

110 In the present study, we hypothesized that fluorescent transgenic tropical freshwater fish and

111 their wild-type progenitor strains used in research and ornamental trade would have poor

112 capacity to overwinter in freshwater systems across Canada, as measured by survival at low

113 temperatures and reproductive capacity after cold rearing. We compared the chronic cold

114 tolerance in three green fluorescent protein (GFP) zebrafish lines and their wild-type progenitor

115 line that are available for research, as well as in three wild-type tropical species/morphs (golden

116 morph of zebrafish, white morph of black tetra, tiger barb) available as fluorescent transgenic

117 lines in the ornamental aquarium trade in the USA, but not currently approved in Canada. 
118 Tolerance to extreme environmental conditions can have reproductive costs in fish (e.g.

119 Schofield et al. 2011). To address this we also examined reproductive parameters in GFP and

120 wild-type zebrafish research lines after long-term rearing at low temperatures, to determine if

121 GFP zebrafish would be able to reproduce after overwintering in cold systems. In addition, we

122 surveyed government and stewardship programs collecting water temperature data to determine

123 typical minimum water temperatures in freshwater systems across Canada. This study has

124 relevance for the development of governmental regulations on use of such fish for commercial

125 and research purposes in Canada and other countries with temperate climates.

126

127 Materials and Methods

128

129 Minimum temperatures in Canada

131 Average winter surface air temperatures for Canada were obtained from Environment and

132 Climate Change Canada (ECCC). Surface and water column water temperatures (rivers and

133 lakes) across Canada were obtained from various Federal, Provincial and International sources

134 (AB Environment; Government of BC Environmental Monitoring System (EMS); Environment

135 and Climate Change Canada; Manitoba Waterstewardship; World Lake Database; Government

136 of Ontario Provincial (Stream) Water Quality Monitoring Network; Government du Quebec,

137 Ministère du Développement durable, de l'Environnement et de la Lutte contre les changements

138 climatiques; BC Lake Stewardship Society). The majority of this data was taken by government

139 employees at designated water quality stations and available online or obtained directly from

140 government employees. The details of how data was collected at each site are not available, and 
141 frequency of monitoring ranges from hourly over several years, to once per season over a single 142 year.

144 Experiment 1: Cold temperature tolerance of tropical species with potential application as 145 fluorescent aquarium fish

147 All experiments were reviewed by institutional animal care committees and conducted under 148 institutional animal care permits meeting guidelines established by the Canadian Council for 149 Animal Care. Golden morph of zebra danios (hereafter referred to as golden zebrafish, white 150 morph of black tetras (hereafter referred to as white tetra), and tiger barbs (all wild-type 151 morphs/species for GloFish ${ }^{\mathrm{TM}}$ lines available in the US, but not available in Canada) were 152 purchased from local aquarium stores or distributors in the Greater Vancouver area, BC, Canada. 153 All three species are domesticated aquarium strains of tropical origin, i.e. zebrafish are native to 154 India, Pakistan, Nepal, Bangladesh, Sri Lanka and Myanmar (Barman 1991), and reportedly 155 tolerate a wide range of temperatures in the wild from as low as $6^{\circ} \mathrm{C}$ to over $38^{\circ} \mathrm{C}$ (see Spence et 156 al. 2008); black tetras are from the Rio Paraguay river basin in South America (see Benine et al. 157 2015); and tiger barbs are native to Sumatra (see Kottelat 1998). Fish were housed in a climate158 controlled room and acclimated at $24^{\circ} \mathrm{C}$ in $38 \mathrm{~L}$ tanks $(n=20$ fish per tank for zebrafish and

159 tetras, $n=15$ fish per tank for tiger barbs, 3 tanks per species) for at least one week. The 160 temperature of two tanks per species (cold-challenge tanks) were then dropped to $20^{\circ} \mathrm{C}$ over a 161 four-day period, and allowed to acclimate to this temperature for at least one week. One tank per 162 species remained at $24^{\circ} \mathrm{C}$ throughout the experiment as a control tank. Fish were fed twice daily 163 with tropical aquarium flakes during acclimation and the experiment. For the experiment, 
164 temperature of the cold challenge tanks was dropped by approximately $1^{\circ} \mathrm{C} /$ day, 6 days a week,

165 by lowering the ambient temperature in the housing room (see Supplemental Figure S1A).

166 Control tanks were held at $24^{\circ} \mathrm{C}$ via submersible heaters. Water temperature was recorded every

16710 min by Tidbit data loggers (Onset Computer Corporation, Bourne, MA). Fish were observed

168 twice a day for feed intake, activity level, and loss of equilibrium until fish stopped feeding or

169 they reached $10^{\circ} \mathrm{C}$ (which ever came first), at which point observations were increased to four

170 times per day. Fish were removed once they could no longer maintain equilibrium, time and

171 temperature recorded, and fish moved to a recovery tank kept at approximately $4^{\circ} \mathrm{C}$ above the

172 cold challenge tanks. Total ammonia, nitrite and $\mathrm{pH}$ were measured in the tanks every 2 days,

173 and $20 \%$ water change performed if nitrite or ammonia levels became detectable. Throughout the

174 experiment, total ammonia nitrate levels remained well below Acute Criterion Magnitude levels

175 as determined by USEPA (2013). Lighting was set to 10:14 light:dark to simulate winter

176 photoperiod. $\mathrm{CL}_{\min }$ determinations were modified from Beitinger et al. (2000) where endpoint

177 measured was loss of equilibrium rather than death although some individuals were not rescued

178 (e.g. those that lost equilibrium during night hours), and in these cases death was considered an

179 equivalent endpoint to loss of equilibrium. $\mathrm{CL}_{\min }$ was calculated as the average temperature at

180 which each tank of individuals within a species lost equilibrium (average \pm s.e.m.), and the

181 temperature at which $50 \%$ of individuals lost equilibrium $\left(\mathrm{LT}_{50}\right)$ for each tank/species was

182 calculated using the dose.p function in MASS package (Venables and Ripley 2002) in R (R Core

183 Team. 2015) and averaged over tanks within species.

184

185 Experiment 2: Chronic cold temperature tolerance and reproductive success of laboratory

186 transgenic and wild-type zebrafish. 
188 Fertilized zebrafish embryos from three lines expressing enhanced GFP driven by cell/tissue

189 specific promoters (e.g. blood vessels, glial cells and epidermis-specific promoters, see Table 1)

190 as well as their wild-type progenitor line (AB line, a common research line) were purchased from

191 the Zebrafish International Resource Centre (ZIRC) at the University of Oregon, Eugene,

192 Oregon. Strains were chosen as they were the most readily available fluorescent models at ZIRC

193 (i.e. available for purchase as embryos), which may increase their potential to be used for

194 research. Fish were raised to adults (estimated as 16 weeks post-hatch) and transferred into a

195 zebrafish rack system held in an environment chamber with precise temperature control. The

196 zebrafish lines were evenly distributed among sixteen, nine-liter tanks in the rack (four

197 tanks/line, approximately 20 fish per tank, 80 fish per line total). As well, an additional 70 fish

198 per line, spread approximately evenly among the four tanks, was included for long-term

199 acclimation at different temperatures (see below). Location of each line on the zebrafish rack

200 system was assigned in a random fashion. After transfer to the zebrafish rack system, all the fish

201 were left for four weeks at $28^{\circ} \mathrm{C}$ to acclimate. Fish were fed daily with commercial zebrafish

202 flake diet and mortality was negligible during this period. At the onset of the experiment,

203 chamber temperature began cooling from $28^{\circ} \mathrm{C}$ to $12^{\circ} \mathrm{C}$ at a rate of approximately $1^{\circ} \mathrm{C} /$ day.

204 Below $12^{\circ} \mathrm{C}$, the rate of temperature decrease was lowered to $\sim 0.1^{\circ} \mathrm{C}$ /day to the minimum

205 temperature available in the environmental chamber $\left(5.1^{\circ} \mathrm{C}\right)$ at which point the trial ended (see

206 Supplemental Figure S1B). Fish were monitored daily and removed once they could no longer

207 maintain equilibrium or died, and time and temperature recorded. Some fish were still alive at

208 the end of the trial, and consequently only $\mathrm{LT}_{50}$ was calculated as above. Loss of equilibriums

209 from specific tanks within a species was not tracked, and consequently $\mathrm{LT}_{50}$ was calculated from 
210 all individuals from all four tanks within a species $(n=80)$. Comparisons of survival curves

211 among lines were performed with survival log-rank analysis, and comparisons of $\mathrm{LT}_{50}$ were

212 performed with one-way ANOVA followed by Student-Newman-Keuls post-hoc test using

213 SigmaPlot (Systat Software Inc., San Jose, CA).

215 During the progressive decline in temperature, 20 individuals of each line (five from each tank) 216 were removed at $28^{\circ} \mathrm{C}, 10^{\circ} \mathrm{C}$ and $8^{\circ} \mathrm{C}$ and held at these temperatures for long-term acclimation

217 (four months) in order to determine whether the fish could produce viable offspring after cold

218 acclimation, once returned to $28^{\circ} \mathrm{C}$. Fish were also removed and held at $6^{\circ} \mathrm{C}(n=10$ per line $)$,

219 however these fish showed 80 to $100 \%$ mortality within the first week of transfer, therefore this

220 treatment was terminated. At the end of the four-month acclimation period, which was staggered

221 so all fish were acclimated for precisely four months, the 8 and $10^{\circ} \mathrm{C}$ acclimation groups were

222 warmed back to $28^{\circ} \mathrm{C}$ over a one week period and, after two weeks at $28^{\circ} \mathrm{C}$, a bulk breed

223 protocol was initiated by placing a breeding tray in each tank for one week, and collecting eggs

224 daily. Total number of individuals per genotype/acclimation temperature group was 16 to 19 , and 225 individual fish were not sexed. Domesticated zebrafish have polygenetic sex determination, i.e.

226 sex can be influenced by environment and unidentified genetic factors (see Liew et al. 2012). All

227 fish used had the same AB wild-type genetic background and had equal juvenile rearing

228 conditions, and as such sex ratios are expected to be similar in each group. However, as sex was

229 not determined this cannot be confirmed and ratio of female:male was unknown. All eggs

230 produced were transferred to zebrafish hatchery trays and the following parameters were

231 recorded: total egg count, total number of eggs fertilized, and total number of eggs hatched. 


\section{Results}

\section{Winter freshwater temperatures for Canadian rivers and lakes}

236 Extensive winter water temperature was gathered from across Canada, with a total of 148 river

237 and 107 lake locations represented. With the exception of coastal Southern BC, surface air

238 temperatures across Canada over the winter months average below freezing (see Figure 1). Due

239 to high mixing in rivers, temperatures are assumed to be uniform throughout the water column in

240 these systems. Surveyed winter river water temperatures were generally $\leq 1{ }^{\circ} \mathrm{C}$ with maximum

241 winter temperature recorded in rivers being $<4{ }^{\circ} \mathrm{C}$ (see Figure 2, Supplemental Table S1). Unlike

242 rivers, lakes often stratify in temperature, particularly in the winter. The majority of lakes in

243 Canada are dimictic, which in Canada generally freeze over and have the warmest, densest water

244 on the bottom (see Horne and Goldman 1994; BCLSS 2014). This temperature is generally

245 around $4^{\circ} \mathrm{C}$, but may be lower if sufficient wind action mixes cooler upper water with the warmer

246 deeper water (see Horne and Goldman 1994). The exception to this is coastal southern BC lakes

247 that are usually monomictic. These lakes mix throughout the winter, with similar temperatures

248 throughout the water column that are generally at or above $4^{\circ} \mathrm{C}$ (Horne and Goldman 1994;

249 BCLSS 2014). Surface and water column measurements in Canadian lakes confirm the majority

250 of lakes having winter temperatures $\leq 4^{\circ} \mathrm{C}$. A few lake locations had recorded minimum

251 temperatures $>4^{\circ} \mathrm{C}$ and up to $6.8^{\circ} \mathrm{C}$, and these lakes were primarily located in southwestern $\mathrm{BC}$

252 (see Figure 2, Supplemental Table S2). Only three lakes had winter temperatures greater than

$25355^{\circ} \mathrm{C}$. The warmest lake, Lake Cowichan, had minimum temperature of $6.8^{\circ} \mathrm{C}$ in February 2016

254 measured at multiple stations across the lake on a single day (obtained from EMS database, BC

255 Ministry of Environment), while in a different location in the same lake, monthly measurements 
256

257

258

259

260

261

262

263

264

265

266

267

268

269

270

271

272

273

274

275

276

277

278

over one year (2012) found a minimum temperature of $5.8^{\circ} \mathrm{C}$ in February (BCLSS 2014). Of the

other two lakes, Twin Lake minimum temperature was taken from temperature profile of the lake measure on a single day in January in 2001 (BCLSS 2004), while Spider Lake temperatures were taken on single days in February in 2010, 2013, 2016 (obtained from EMS database, BC

Ministry of Environment). Considering the scarcity of data in these warmer lakes, the temperatures may not necessarily represent the coldest normal winter temperatures in the lakes.

For other lakes, water column profile data for lakes are rarely taken, and warmer temperatures may be present at lower depths in dimictic lakes than those recorded, although these temperatures are not expected to be greater than $4^{\circ} \mathrm{C}$.

\section{Cold temperature tolerance of tropical species with potential transgenic applications}

In the cold temperature trial using equivalent wild-type ornamental aquarium morphs and/or species as GloFish ${ }^{\circledR}\left(\right.$ Experiment 1), all species lost equilibrium over a $1-2^{\circ} \mathrm{C}$ temperature range (6.6-4. $8^{\circ} \mathrm{C}$ for golden zebrafish, $10.5-9.5^{\circ} \mathrm{C}$ for white tetras, and $13.6-12.6^{\circ} \mathrm{C}$ for tiger barbs, see Figure 3). Golden zebrafish had the greatest tolerance to cold water in terms of $\mathrm{CL}_{\text {min }}$, followed by white tetras and tiger barbs (see Table 2). Average $\mathrm{LT}_{50}$ were slightly lower than average $\mathrm{CL}_{\min }$ for all species, but this difference was less than $0.3^{\circ} \mathrm{C}$ (see Table 2). If $\mathrm{CL}_{\min }$ and $\mathrm{LT}_{50}$ were calculated with tanks pooled per species as per Experiment 2, this did not greatly influence $\mathrm{CL}_{\text {min }}$ measurements, although increased $\mathrm{LT}_{50}$ measurements so that they were closer (within $0.1^{\circ} \mathrm{C}$ ) to $\mathrm{CL}_{\min }$ measurements (i.e. $5.59 \pm 0.03^{\circ} \mathrm{C}$ for golden zebrafish, $9.99 \pm 0.02^{\circ} \mathrm{C}$ for tetra, $13.45 \pm 0.03^{\circ} \mathrm{C}$ for barb). All species decreased activity and feeding with decreasing temperature and ceased feeding as temperatures continued to drop (see Figure 3). Both zebrafish and tetras 
279 ceased moving and rested on the bottom of the aquaria prior to loss of equilibrium, while barbs

280 continued moderate to medium activity until loss of equilibrium. Of the fish removed at loss of

281 equilibrium, zebrafish and tetra individuals were rescuable (i.e. returned to regular activity and

282 feeding after warming to $24^{\circ} \mathrm{C}$ ), but all tiger barbs died once moved to recovery tanks. There

283 were no mortalities in control fish held at $24^{\circ} \mathrm{C}$ during the experiment and they had high activity

284 and feeding level throughout the experiment.

286 In the cold temperature trial for research lines of zebrafish (Experiment 2), the y1 line had a 287 more rapid decrease in survival with decreasing temperature (Figure $4, P=0.025$ to 0.035 ) as 288 well as higher $\operatorname{LT}_{50}(P<0.001$, see Table 2$)$ than the other lines, although the $\mathrm{LT}_{50}$ of all lines 289 was within less than $1^{\circ} \mathrm{C}$ of each other $\left(5.38-5.90^{\circ} \mathrm{C}\right)$. There were no other differences

290 observed. In Experiment 1, when $\mathrm{LT}_{50}$ was calculated with pooled tanks as in Experiment 2, 291 values were within $0.1^{\circ} \mathrm{C}$ of $\mathrm{CT}_{\text {min. }}$. As such, it is presumed that $\mathrm{LT}_{50}$ values in Experiment 2 as 292 calculated with pooled tanks are accurate measurements of cold tolerance. Survival of control 293 fish at $28^{\circ} \mathrm{C}$ was not specifically tracked, although fish reared at $28^{\circ} \mathrm{C}$ during this time and for an 294 additional month (four months total, see reproductive performance below) had 85-95\% survival 295 (see Table 3).

297 Effect of cold-water rearing on reproductive performance of GFP transgenic and wild-type 298 zebrafish

300 Survival during the four-month holding periods at 28,10 and $8^{\circ} \mathrm{C}$ was not significantly affected 301 by zebrafish line, acclimation temperature, or their interactions $(P=0.7342,0.8074$, and 0.6341 
302 respectively) and ranged from $80-95 \%$ over the four-month period (see Table 3 ). All fish groups

303 from all acclimation temperatures laid eggs. There were large variations in the total number of

304 eggs produced by the different lines of zebrafish held at different temperatures, although there

305 was no significant factor effects of genotype or temperature on the total number of eggs laid $(P=$

3060.392 and 0.551 respectively), the total number of fertilized eggs $(P=0.394$ and 0.472

307 respectively), or the total number of eggs hatched $(P=0.419$ and 0.693 respectively, see Table

308 3). As number of available females per group was not known, and therefore cannot be confirmed

309 to be equal among groups, results related to total egg count as estimated of average productivity

310 should be interpreted with caution.

\section{Discussion}

314 This is the first published report of cold tolerance of black tetras and tiger barbs, and the first

315 published study examining the effect of fluorescent transgenesis on cold tolerance where

316 background strain and rearing conditions were controlled for. Of the tropical species examined,

317 only zebrafish (wild-type, GFP transgenic, and golden varieties) had minimum water

318 temperature tolerances $\left(5.38\right.$ to $\left.5.90^{\circ} \mathrm{C}\right)$ within the range of winter water temperatures recorded

319 for Canada. However, almost all of surveyed lakes and rivers had winter temperatures lower than

320 tolerances of these zebrafish strains (see Figure 2). In addition, long-term rearing of wild-type

321 and GFP transgenic zebrafish at $6^{\circ} \mathrm{C}$ resulted in high mortality, indicating their functional

322 minimum temperature tolerance is higher than indicated by modified $\mathrm{CL}_{\min }$ or $\mathrm{LT}_{50}$. Long-term

323 rearing at $8^{\circ} \mathrm{C}$ did not result in a significant increase in mortality, indicating the functional

324 minimum temperature tolerance of zebrafish is between 6 and $8^{\circ} \mathrm{C}$. Only one surveyed lake in 
325 Southwestern BC had winter temperatures within this range, and water temperatures in the same

326 lake but different location and year were less than $6^{\circ} \mathrm{C}$, indicating zebrafish lines would be

327 unlikely to persist over multiple winters even in the warmest lakes, based on temperature

328 tolerance data alone. Zebrafish released to natural systems would also be expected to be further

329 limited by varying food supply, competition and predation from native fish, and altering abiotic

330 factors such as oxygen. Fluorescent models may have even further limited persistence, as

331 currently marketed RFP Glofish ${ }^{\circledR}$ zebrafish are reported to be preyed on at a greater rate (Hill et

332 al. 2011) and have decreased spawning success and fitness (Howard et al. 2015). Of the other

333 two species examined, the higher minimum tolerated temperatures of the white tetra $\left(9.95^{\circ} \mathrm{C}\right)$

334 and tiger barb $\left(13.36^{\circ} \mathrm{C}\right)$ indicate they would not be able to overwinter in surveyed freshwater

335 systems in Canada. The tiger barbs in particularly displayed poor acclimation to lowering

336 temperatures as they had the highest $\mathrm{CL}_{\min }$, were not rescuable after loss of equilibrium, and

337 unlike zebrafish and tetras did not display modified activity as they approached $\mathrm{CL}_{\min }$.

339 These results provide empirical data to the support limited potential for invasiveness as estimated

340 by the FISK tool in the USA (Hill et al. 2014), the tropical origins of the species in question, and

341 a lack of establishment for these species in temperate climates in North America. All three

342 species are among the most commonly sold wild-type ornamental aquarium fish (Gertzen et al.

343 2008; Strecker et al. 2011). Release of ornamental aquarium fish to natural systems in Canada

344 and elsewhere is commonplace (e.g. Marson et al. 2009 found up to $2 \%$ unwanted aquarium fish

345 in Canada were released to the wild), indicating there would be a high propagule pressure of

346 release of these fish throughout North America. Despite this, there are no reports of established

347 populations of these species in North America (Hill et al. 2014). Non-native occurrences of 
348 zebrafish have been limited to temporary local establishments in New Mexico, USA and

349 Columbia (Welcome 1988; Nico et al. 2013a); black tetras from the aquarium trade were

350 transiently established in a Colorado hot spring, and isolated occurrences have been reported in

351 Florida and Louisiana (Nico and Fuller 2005), but there are no known established populations in

352 temperate regions; and tiger barbs have numerous isolated occurrences have been reported in

353 Southern US, but failed to establish (Courtenay and Hensley 1979; Howells 2001; Nico et al.

$3542013 b$ ). In extensive surveys of waterbodies adjacent to and surrounding ornamental aquarium

355 facilities in Florida, USA, both wild-type and Glofish ${ }^{\mathrm{TM}}$ zebrafish, as well as black tetras and

356 tiger barbs were found adjacent to facilities, but not detected greater than $500 \mathrm{~m}$ away (Tuckett et

357 al. 2017), indicating limited ability to establish and spread after escape. The authors identified

358 potential causes for lack of establishment of escaped tropical fish, including abiotic challenges,

359 presence of predators and competitors, and bright colouration and poor body shape for predator

360 avoidance and competition success (Tuckett et al. 2017). It is worth noting that localized areas of

361 warmer water, such as hot springs (Mayhood 1995; Wright 2002) and areas downstream of warm

362 industrial effluent (Mills et al. 1993; Starling et al. 1995; Peterson et al. 2005), can result in

363 pockets of local establishment of exotic fish species otherwise unable to withstand temperate

364 water temperatures and able to persist and reproduce within a small spatial range, although any

365 potential impact of this would be localized. Consequently, local conditions and potential scale of

366 impacts should be considered when determining the establishment potential of various exotic

367 transgenic fish species in Canada.

369 This is the first report of low-temperature tolerance of white tetras or tiger barbs, and their high

370 minimum temperature tolerance is expected given their tropical origin. Minimum temperature 
371 tolerance of golden zebrafish, as well as wild-type and GFP transgenic research lines of

372 zebrafish, was similar to that reported for wild-type $\left(5.3 \pm 0.2^{\circ} \mathrm{C}\right)$ and red fluorescent protein

373 (RFP) zebrafish derived from the wild-type strain $\left(5.6 \pm 0.2^{\circ} \mathrm{C}\right)$ under similar experimental

374 conditions (Cortemeglia and Beitinger 2006). The $\mathrm{CL}_{\min }$ of the golden zebrafish in the current

375 study was lower than that reported in striped wild-type, suggesting the currently marketed

376 GloFish zebrafish in a golden morph background may have less ability to withstand cold

377 temperatures than those in a striped background (Cortemeglia and Beitinger 2006), although as

378 the different fish morphs and strains were not examined in parallel, direct comparisons cannot be

379 made. Of the research lines of GFP transgenic zebrafish, only the y1 line had significantly higher

$380 \mathrm{CL}_{\min }$ than the other GFP and wild-type lines, indicating some transgenes may alter temperature

381 tolerance of fish. In general, GFP and other fluorescent proteins are considered neutral - i.e. their

382 presence does not significantly affect cell function (see Stewart 2001, 2006). However, mouse

383 (Mus musculus L., 1758) models with very high levels of universal GFP expression have been

384 reported to have poor early developmental competence (Devgan et al. 2004) and renal defects

385 and high adult mortality (Guo et al. 2007), and high cardiac-specific GFP expression increased

386 cardiomyopathy resulting in high mortality (Huang et al. 2000), while models with lower levels

387 of GFP expression did not show significant pathology. As well, Tao et al. (2007) found RFP

388 (DsRed) expressing haemopoetic stem cells had poor growth, while GFP-expressing cells did

389 not, demonstrating different fluorescent transgene constructs may have different effects. The

390 three transgenic research lines in the current study used similar GFP gene coding regions but

391 different promoters, resulting in different localized expression of GFP. The y1 line with inferior

392 minimum temperature tolerance expressed GFP in blood vessels. Functional failure of circulation

393 is thought to be a component limiting cold tolerance (see Pörtner 2001), and it is possible that 
394 GFP expression in the blood vessels had a negative impact on circulation and hence tolerance of

395 the line to low temperatures. Liu and Liu (2012) also found the yl line had unspecific vascular

396 expression and altered embryonic expression profiles of over 230 genes including immune

397 response and embryonic development genes, suggesting this line may have overall altered

398 response to normal or pathological conditions. Expression of GFP in glial cells (line mi2001) and

399 developing epidermis (line zp4) did not appear to impact minimum temperature tolerance in

400 zebrafish. Whether commercial strains with potentially ubiquitous expression (e.g. currently

401 marketed Glofish $\left.{ }^{\circledR}\right)$ would have greater potential for altered cold tolerance than laboratory

402 strains with more directed transgene expression has not been assessed.

404 The differences in laboratory strains confirms other studies demonstrating the importance of 405 considering each unique line separately when conducting tolerance or other risk assessment406 related studies (e.g. Tuckett et al. 2016; Leggatt et al. 2017; see Devlin et al. 2015). Intraspecific

407 variation, including differences among different lines of transgenics, should also be considered in 408 risk assessment. Intraspecific variation in cold tolerance has been demonstrated in another 409 ornamental fish, green swordtails Xiphophorus hellerii Heckel, 1848, where cold tolerance of 410 escaped populations was greater than populations obtained from commercial suppliers (Tuckett 411 et al. 2016). In salmonids, different lines of growth-enhanced transgenic salmon and trout, as 412 well as domestication and domestication $\mathrm{x}$ transgenesis interactions, can influence the ability to 413 survive in semi-natural stream environments (Crossin et al. 2015; Leggatt et al. 2016; Leggatt et 414 al. 2017). In the ornamental aquarium trade, domestication level and life history experience may 415 differ greatly among intraspecific populations, while in the laboratory zebrafish long-term colony 416 maintenance may result in genetic shifts in different populations. The potential for intraspecific 
417 variation to influence thermal tolerance or uncertainty in risk assessments should be addressed,

418 particularly in species where thermal tolerance is closely aligned with the environments being 419 assessed.

421 The reproduction trial demonstrates that wild-type and GFP transgenic zebrafish lines examined 422 are capable of producing viable embryos after long-term rearing at temperatures as low as $8^{\circ} \mathrm{C}$.

423 Therefore, fluorescent zebrafish have the potential to reproduce in warmer water refuge areas

424 should they survive the winter. Previous studies examining the effects of fluorescent transgenes

425 on reproductive success or preferences in zebrafish depend on the variable examined and 426 transgenic group considered. RFP and wild-type zebrafish had similar age at maturity for females

427 as well as male and female fecundity (Howard et al. 2015). In a population containing equal 428 numbers of GFP and wild-type zebrafish allowed to breed for one week, GFP zebrafish had no 429 apparent reproductive advantage or disadvantage over wild-type (Gong et al. 2003), while in a 430 serial breeding experiment Howard et al. (2015) found the frequency of the RFP transgene 431 declined rapidly and was eliminated in most populations after 15 generations indicating a strong 432 bias against the RFP transgene in reproduction. Other studies found both wild-type and RFP 433 zebrafish females preferred to associate with RFP rather than wild-type males, but did not differ

434 in number of mating bouts (Owen et al. 2012), lower mating success and aggression levels in 435 RFP male zebrafish (Howard et al. 2015), greater aggression in RFP zebrafish (Jha 2010), and no 436 effect of RFP transgene on social partner preferences in zebrafish (Snekser et al. 2006). The

437 inconsistent effect of RFP and GFP transgenes on zebrafish reproductive effects indicate

438 fluorescent transgenes do not impart an innate disadvantage to zebrafish, rather the effects of the 439 transgenes are influenced by other factors, potentially including transgene type or strain utilized, 
440 rearing history, experimental conditions, and genotype x environment interactions. However, any

441 potential reproduction of tropical fluorescent transgenic fish is expected to be negated by poor

442 cold tolerance, resulting in lack of establishment in Canadian waters.

\section{Acknowledgments}

446 This project was funded by Canadian Regulatory System for Biotechnology to RHD and JGR.

447 Thank you to Paul Hebert at ECCC, as well as Tom Arsenault at ECCC, Dawn and Kristine at 448 BC Lake Stewardship Society, Serge Hebert at QC Ministère du Développement durable, de

449 l'Environnement et de la Lutte contre les changements climatiques, and Doreen LeClair and

450 Alberta Environment for providing minimum water temperature data within Canada. Thank you

451 to Janet Beardall, Sherry Walker, Colin McGowan, Janice Oakes, Breanna Watson, Jeremy

452 Donohoe, and Dr. Christine MacWilliams for assistance with this study.

\section{References}

455 Amsterdam, A., Lin, S., and Hopkins, N. 1995. The Aequorea victoria green fluorescent protein 456 can be used as a reporter in live zebrafish embryos. Dev. Biol. 171(1): 123-129.

457 Barbosa, J.S., Di Giaimo, R., Gotz, M., and Ninkovic, J. 2016. Single-cell in vivo imaging of 458 adult neural stem cells in the zebrafish telencephalon. Nat. Protoc. 11(8): 1360-1370.

459 Barman, R.P. 1991. A taxonomic revision of the Indo-Burmese species of Danio Hamilton 460 Buchanan (Pisces: Cyprinidae). Records of the Zoological Survey of India, 137: i-viii, 1-91. 461 BCLSS. 2004. The importance of Twin Lake and its watershed. British Columbia Lake $462 \quad$ Stewardship Society, Kelowna, BC. p. 8. 
463 BCLSS. 2014. Cowichan Lake 2004-2013. British Columbia Lake Stewardship Society, $464 \quad$ Kelowna, BC. p. 4.

465 Beitinger, T.L., Bennett, W.A., and McCauley, R.W. 2000. Temperature tolerances of North 466 American freshwater fishes exposed to dynamic changes in temperature. Environ. Biol. $467 \quad$ Fishes, 58: 237-275.

468 Benine, R.C., Melo, B.F., Castro, R.M.C., and Oliveira, C. 2015. Taxonomic revision and 469 molecular phylogeny of Gymnocorymbus Eigenmann, 1908 (Teleostei, Characiformes, $470 \quad$ Characidae). Zootaxa, 3956(1): 1-28.

471 Bernardos, R.L., and Raymond, P.A. 2006. GFAP transgenic zebrafish. Gene Expr. Patterns, $472 \quad 6(8): 1007-1013$.

473 CFGC. 2015. Sales of GoFish ${ }^{\circledR}$ in California. State of California, Department of Fish and 474 Wildlife:

475 http://www.fgc.ca.gov/meetings/2015/Apr/Exhibits/2021A_2011_LTR_Glofish_CA_Bonham $476 \quad$ Chuck.pdf.

477 Chen, C.H., Puliafito, A., Cox, B.D., Primo, L., Fang, Y., Di Talia, S., and Poss, K.D. 2016.

478 Multicolor cell barcoding technology for long-term surveillance of epithelial regeneration in 479 zebrafish. Dev. Cell, 36(6): 668-680.

480 Cortemeglia, C., and Beitinger, T.L. 2005. Temperature tolerances of wild-type and red 481 transgenic zebra danios. Trans. Am. Fish. Soc. 134: 1431-1437.

482 Cortemeglia, C., and Beitinger, T.L. 2006. Projected US distributions of transgenic and wildtype 483 zebra danios, Danio rerio, based on temperature tolerance data. J. Therm. Biol. 31: 422-428. 
484 Cortemeglia, C., Beitinger, T.L., Kennedy, J.H., and Walters, T. 2008. Field confirmation of 485 laboratory-determined lower temperature tolerance of transgenic and wildtype zebra danios, 486 Danio rerio. Am. Midl. Nat. 160(2): 477-479.

487 Courtenay, W.R., and Hensley, D.A. 1979. Survey of introduced non-native fishes. Phase I 488 Report. Introduced exotic fishes in North America: status 1979. National Fishery Research $489 \quad$ Laboratory, U.S. Fish and Wildlife Service, Gainesville, FL.

490 Crossin, G.T., Sundström, L.F., Vandersteen, W.E., and Devlin, R.H. 2015. Early life-history 491 consequences of growth-hormone transgenesis in rainbow trout reared in stream ecosystem 492 mesocosms. PLoS ONE, 10: e0120173.

493 Devgan, V., Rao, M.R.S., and Seshagiri, P.B. 2004. Impact of embryonic expression of enhanced 494 green fluorescent protein on early mouse development. Biochem. Biophys. Res. Commun. 313(4): 1030-1036.

Devlin, R.H., Sundström, L.F., and Leggatt, R.A. 2015. Assessing ecological and evolutionary consequences of growth-accelerated genetically engineered fishes. BioScience, 65(7): 685-

499 Gertzen, E., Familiar, O., and Leung, B. 2008. Quantifying invasion pathways: fish introductions 500 from the aquarium trade. Can. J. Fish. Aquat. Sci. 65(7): 1265-1273.

501 Gong, Z., Wan, H., Tay, T.L., Wang, H., Chen, M., and Yan, T. 2003. Development of 502 transgenic fish for ornamental and bioreactor by strong expression of fluorescent proteins in the skeletal muscle. Biochem. Biophys. Res. Commun. 308: 58-63.

504 Guo, J.K., Cheng, E.C., Wang, L., Swenson, E.S., Ardito, T.A., Kashgarian, M., Cantley, L.G., 505 and Krause, D.S. 2007. The commonly used $\beta$-actin-GFP transgenic mouse strain develops a 506 distinct type of glomerulosclerosis. Transgenic Res. 16(6): 829-834. 
507 Hill, J.E., Kapuscinski, A.R., and Pavlowich, T. 2011. Fluorescent transgenic zebra danio more 508 vulnerable to predators than wild-type fish. Trans. Am. Fish. Soc. 140(4): 1001-1005.

509 Hill, J.E., Lawson, L.L., and Hardin, S. 2014. Assessment of the risks of transgenic fluorescent 510 ornamental fishes to the United States Using the Fish Invasiveness Screening Kit (FISK).

511 Trans. Am. Fish. Soc. 143(3): 817-829.

512 Horne, A.J., and Goldman, C.R. 1994. Limnology, 2nd Edition. McGraw-Hill, Inc., New York.

513 Howard, R.D., Rohrer, K., Liu, Y.Y., and Muir, W.M. 2015. Mate competition and evolutionary 514 outcomes in genetically modified zebrafish (Danio rerio). Evolution, 69(5): 1143-1157.

515 Howells, R.G. 2001. Introduced non-native fishes and shellfishes in Texas waters: an updated list 516 and discussion. Texas Parks and Wildlife Department Management Data Series No 188, $517 \quad$ Austin, Texas.

518 Huang, W.Y., Aramburu, J., Douglas, P.S., and Izumo, S. 2000. Transgenic expression of green 519 fluorescence protein can cause dilated cardiomyopathy. Nat. Med. 6(5): 482-483.

520 Jha, P. 2010. Comparative study of aggressive behaviour in transgenic and wildtype zebrafish 521 Danio rerio (Hamilton) and the flying barb Esomus danricus (Hamilton), and their 522 susceptibility to predation by the snakehead Channa striatus (Bloch). Ital. J. Zool. 77(1): 102523109.

524 Kottelat, M. 1998. Fishes of the Nam Theuan and Xe Bangfai basins, Laos, with diagnoses of 525 twenty-two new species (Teleostei: Cyprinidae, Balitoridae, Cobitidae, Coiidae and 526 Odontobutidae). Ichthyol. Explor. Freshw. 9(1): 1-128.

527 Lawson, N.D., and Weinstein, B.M. 2002. In vivo imaging of embryonic vascular development 528 using transgenic zebrafish. Dev. Biol. 248(2): 307-318. 
529 Leggatt, R.A., Sundström, L.F., Vandersteen, W.E., and Devlin, R.H. 2016. Alternate directed

530 anthropogenic shifts in genotype result in different ecological outcomes in coho salmon

$531 \quad$ Oncorhynchus kisutch fry. PLoS ONE, 11(2): e0148687.

532 Leggatt, R.A., Sundstrom, L.F., Woodward, K., and Devlin, R.H. 2017. Growth-enhanced

533 transgenic coho salmon (Oncorhynchus kisutch) strains have varied success in simulated

534 streams: implications for risk assessment. PLoS ONE, 12(1).

535 Liew, W.C., Bartfai, R., Lim, Z., Sreenivasan, R., Siegfried, K.R., and Orban, L. 2012. Polygenic

536 sex determination system in zebrafish. PLoS ONE, 7(4): e34397.

537 Lin, C.Y., Chiang, C.Y., and Tsai, H.J. 2016. Zebrafish and Medaka: new model organisms for 538 modern biomedical research. J. Biomed. Sci. 23.

539 Liu, Z.B., and Liu, F. 2012. Cautious use of flila:EGFP transgenic zebrafish in vascular

$540 \quad$ research. Biochem. Biophys. Res. Commun. 427(1): 223-226.

541 Marson, D., Cudmore, B., Drake, D.A.R., and Mandrak, N.E. 2009. Summary of a survey of

542 aquarium owners in Canada. Canadian Manuscript Report of Fisheries and Aquatic Sciences, $5432905: \mathrm{iv}+20$ p.

544 Mayhood, D.M. 1995. The fishes of the Central Canadian Rockies ecosystem 950408.

545 Freshwater Research Limited, Calgary, AB.

546 Mills, E.L., Leach, J.H., Carlton, J.T., and Secor, C.L. 1993. Exotic species in the Great Lakes: A 547 history of biotic crises and anthropogenic introductions. J. Gt. Lakes Res. 19(1): 1-54.

548 Nico, L., and Fuller, P. 2005. Gymnocorymbus ternetzi. USGS Nonindigenous Aquatic Species

549 Database. Gainesville, FL.

550 Nico, L., Fuller, P., and Loftus, B. 2013a. Danio rerio. USGS Nonindigenous Aquatic Species 551 Database. Gainesville, FL. 
552 Nico, L., Fuller, P., Neilson, M., and Loftus, B. 2013b. Systomus tetrazona. USGS

553 Nonindigenous Aquatic Species Database. Gainesville, FL.

554 Owen, M.A., Rohrer, K., and Howard, R.D. 2012. Mate choice for a novel male phenotype in 555 zebrafish, Danio rerio. Anim. Behav. 83(3): 811-820.

556 Peterson, M.S., Slack, W.T., and Woodley, C.M. 2005. The occurrence of non-indigenous Nile 557 tilapia, Oreochromis niloticus (Linneaus) in coastal Mississippi, USA: ties to aquaculture and 558 thermal effluent. Wetlands, 25(1): 112-121.

559 Pörtner, H.O. 2001. Climate change and temperature-dependent biogeography: oxygen limitation 560 of thermal tolerance in animals. Naturwissenschaften, 88(4): 137-146.

561 Pyati, U.J., Cooper, M.S., Davidson, A.J., Nechiporuk, A., and Kimelman, D. 2006. Sustained 562 Bmp signaling is essential for cloaca development in zebrafish. Development, 133(11): 22755632284.

564 R Core Team. 2015. R: A language and environment for statistical computing. R Foundation for 565 Statistical Computing, Vienna, Austria.

566 Schofield, P.J., Peterson, M.S., Lowe, M.R., Brown-Peterson, N.J., and Slack, W.T. 2011.

567 Survival, growth and reproduction of non-indigenous Nile tilapia, Oreochromis niloticus

568 (Linnaeus 1758). I. Physiological capabilities in various temperatures and salinities. Mar.

$569 \quad$ Freshw. Res. 62(5): 439-449.

570 Snekser, J.L., McRobert, S.P., Murphy, C.E., and Clotfelter, E.D. 2006. Aggregation behavior in $571 \quad$ wildtype and transgenic zebrafish. Ethology, 112(2): 181-187.

572 Spence, R., Gerlach, G., Lawrence, C., and Smith, C. 2008. The behaviour and ecology of the 573 zebrafish, Danio rerio. Biol. Rev. Camb. Philos. Soc. 83(1): 13-34. 
574 Starling, S.M., Bruckler, R.M., Strawn, R.K., and Neill, W.H. 1995. Predicting the lethality of

575 fluctuating low temperatures to blue tilapia. Trans. Am. Fish. Soc. 124: 112-117.

576 Stewart, C.N. 2001. The utility of green fluorescent protein in transgenic plants. Plant Cell Rep.

$577 \quad 20(5): 376-382$.

578 Stewart, C.N. 2006. Go with the glow: fluorescent proteins to light transgenic organisms. Trends

579 Biotechnol. 24(4): 155-162.

580 Strecker, A.L., Campbell, P.M., and Olden, J.D. 2011. The aquarium trade as an invasion

581 pathway in the Pacific Northwest. Fisheries, 36(2): 74-85.

582 Tao, W., Evans, B.G., Yao, J., Cooper, S., Cornetta, K., Ballas, C.B., Hangoc, G., and

583 Broxmeyer, H.E. 2007. Enhanced green fluorescent protein is a nearly ideal long-term

584 expression tracer for hematopoietic stem cells, whereas DsRed-Express fluorescent protein is

585 not. Stem Cells, 25(3): 670-678.

586 Tuckett, Q.M., Ritch, J.L., Lawson, K.M., and Hill, J.E. 2017. Landscape-scale survey of non-

587 native fishes near ornamental aquaculture facilities in Florida, USA. Biol. Invasions, 19: 223$588 \quad 237$.

589 Tuckett, Q.M., Ritch, J.L., Lawson, K.M., Lawson, L.L., and Hill, J.E. 2016. Variation in cold

590 tolerance in escaped and farmed non-native green swordtails (Xiphophorus hellerii) revealed

591 by laboratory trials and field introductions. Biol. Invasions, 18(1): 45-56.

592 Udvadia, A.J., and Linney, E. 2003. Windows into development: historic, current, and future

593 perspectives on transgenic zebrafish. Dev. Biol. 256(1): 1-17.

594 USEPA. 2013. Aquatic life ambient water quality criteria for ammonia - Freshwater 1989. EPA-

595 822-R-13-001, Washington, DC.

596 Venables, W.N., and Ripley, B.D. 2002. Modern Applied Statistics with S. Springer, New York. 
597 Welcome, R.L. 1988. International introductions of inland aquatic species 294. FAO Fisheries 598 Technical Paper.

599 Wright, D. 2002. Intentional introductions of alien species of fish: Have we learned from our 600 mistakes? In Alien Invaders in Canada's Waters, Wetlands, and Forests. Edited by R. Claudi, 601 P. Nantel and E. Muckle-Jeffs. Canadian Forest Service, Science Branch, NRC, Ottawa. pp. $602 \quad 201-217$.

603

604 


\section{Figure Legends}

606

607 Figure 1: Surface air temperatures in Canada from December through February, averaged from

608 1981-2010. Copy of Temperature Climatology-Map-Average-Dec-Jan-Feb (Winter) copied

609 from the Government of Canada, Environment and Climate Change Canada

610 (https://weather.gc.ca/saisons/image_e.html?format=clim_stn\&season=djf\&type=temp).

611

612 Figure 2: Minimum winter water temperature distribution of surveyed lakes and rivers across

613 Canada. $n=148$ for river and 107 for lakes.

614

615 Figure 3: Survival during gradual cold exposure for three freshwater ornamental aquarium

616 species used in production of commercial fluorescent ornamental lines. Water temperature was

617 dropped by $1^{\circ} \mathrm{C} /$ day, 6 days/week starting at $20^{\circ} \mathrm{C}$ (40 zebrafish Danio rerio Hamilton, $1822 ; 40$

618 tetras Gymnocorymbus ternetzi Boulenger, 1895; 30 tiger barbs Puntius tetrazona Bleeker, 1855,

619 divided into 2 tanks per species). Arrows indicate times at which golden zebrafish (solid

620 line/arrows), white tetras (dotted line/arrows), and tiger barbs (dashed line/arrow) altered

621 behaviour with decreasing temperature.

622

623 Figure 4: Survival during gradual cold exposure for three lines of GFP-transgenic zebrafish (y1, 624 mi2001, zp4, Danio rerio Hamilton, 1822) and their wild-type progenitor line (AB).

625 Temperature was dropped from $28^{\circ} \mathrm{C}$ to $12^{\circ} \mathrm{C}$ at a rate of approximately $1^{\circ} \mathrm{C}$ per day, then from $62612^{\circ} \mathrm{C}$ to $5.1^{\circ} \mathrm{C}$ at a rate of approximately $0.1^{\circ} \mathrm{C}$ per day (80 fish per line, divided into 4 tanks). 
628 Table 1: Zebrafish (Danio rerio Hamilton, 1822) research lines used to examine the influence of

629 enhanced green fluorescent protein (eGFP) transgenesis on chronic low-temperature tolerance

630 and effects of cold acclimation on reproduction.

\begin{tabular}{|c|c|c|c|c|}
\hline Fish line & Fish genotype & Transgene construct & eGFP localization & Reference \\
\hline \multirow[t]{2}{*}{ fli1 (y1) } & $\operatorname{Tg}\left(\right.$ Fli1a:EGFP) ${ }^{\mathrm{y} 1}$ & eGFP driven by Fli-1 protein & developing and & Lawson and \\
\hline & & promoter & adult blood vessels & Weinstein 2002 \\
\hline \multirow[t]{3}{*}{ gfap (mi2001) } & $\operatorname{Tg}(\text { gfap:GFP })^{\text {mi2001 }}$ & eGFP driven by glial fibrillary & developing and & Bernardos and \\
\hline & & acidic protein promoter & adult glial cells & Raymond 2006, \\
\hline & & & & Barbosa et al. 2016 \\
\hline \multirow[t]{2}{*}{ msxb (zp4) } & TG(-6.5msx 1b: & eGFP driven by muscle segment & ventral epidermis & Pyati et al. 2006 \\
\hline & EGFP) $)^{\mathrm{zp} 4}$ & homeobox $1 \mathrm{~b}$ promoter & during development & \\
\hline AB (wild- & wild-type & none & none & https://zfin.org/ZDB- \\
\hline type) & progenitor line & & & GENO-960809-7 \\
\hline
\end{tabular}

631 Note: All transgenic lines were produced in the AB wild-type line and purchased from the

632 Zebrafish International Resource Centre at the University of Oregon, Eugene, Oregon. 
634 Table 2: Chronic lethal minimums $\left(\mathrm{CL}_{\min }\right)$ and temperature at which $50 \%$ of fish lost equilibrium

$635\left(\mathrm{LT}_{50}\right)$ in wild-type and transgenic tropical freshwater fish with transgenic applications in

636 research and commercial ornamental trade.

\begin{tabular}{|c|c|c|}
\hline species/line & $\mathrm{CL}_{\min }\left({ }^{\circ} \mathrm{C}\right)$ & $\mathrm{LT}_{50}\left({ }^{\circ} \mathrm{C}\right)$ \\
\hline \multicolumn{3}{|l|}{ Experiment 1} \\
\hline golden zebrafish (Danio rerio & $5.53 \pm 0.08$ & $5.24 \pm 0.03$ \\
\hline \multicolumn{3}{|l|}{ Hamilton, 1822) } \\
\hline white tetra (Gymnocorymbus & $9.95 \pm 0.03$ & $9.81 \pm 0.00$ \\
\hline \multicolumn{3}{|l|}{ ternetzi Boulenger, 1895) } \\
\hline tiger barb (Puntius tetrazona & $13.36 \pm 0.02$ & $13.20 \pm 0.03$ \\
\hline \multicolumn{3}{|l|}{ Bleeker, 1855) } \\
\hline \multicolumn{3}{|l|}{ Experiment 2 zebrafish lines } \\
\hline wild-type & $\mathrm{n} / \mathrm{a}$ & $5.41 \pm 0.06^{\mathrm{a}}$ \\
\hline y1 & $\mathrm{n} / \mathrm{a}$ & $5.90 \pm 0.05^{b}$ \\
\hline $\operatorname{mi} 2001$ & $\mathrm{n} / \mathrm{a}$ & $5.45 \pm 0.06^{\mathrm{a}}$ \\
\hline zp4 & $\mathrm{n} / \mathrm{a}$ & $5.38 \pm 0.07^{\mathrm{a}}$ \\
\hline
\end{tabular}

Note: Data are given as mean \pm s.e.m, and letters $(a, b)$ indicate significant difference among fish

638 lines in Experiment $2(P<0.05)$. Experiment 1: $n=2$ tanks with 20 (golden zebrafish and white

639 tetra) or 15 (tiger barb) fish per tank. Experiment 2: $n=80$ fish per genotype.

640

641 
642 Table 3: Survival of GFP transgenic and wild-type zebrafish (Danio rerio Hamilton, 1822) lines

643 over a four-month period held at different temperatures ( $n=20$ fish per line and temperature), and

644 total number of eggs laid, fertilized and hatched over 7 days breeding after returning to $28^{\circ} \mathrm{C}$.

\begin{tabular}{lccc}
\hline & $28^{\circ} \mathrm{C}$ & $10^{\circ} \mathrm{C}$ & $8^{\circ} \mathrm{C}$ \\
\hline \multicolumn{3}{l}{ Survival (\%) } & during acclimation \\
y1 & 90 & 90 & 90 \\
mi2001 & 95 & 90 & 80 \\
zp4 & 90 & 90 & 85 \\
wild-type & 85 & 80 & 80 \\
Total number of eggs laid & & \\
y1 & 65 & 125 & 32 \\
mi-2001 & 57 & 100 & 2 \\
zp4 & 15 & 5 & 5 \\
wild-type & 2 & 102 & 184
\end{tabular}

Total number of fertilized eggs

$\begin{array}{llll}\mathrm{y} 1 & 63 & 38 & 21\end{array}$

mi-2001 $\quad 50 \quad 91 \quad 1$

$\begin{array}{llll}\text { zp4 } & 13 & 2 & 1\end{array}$

$\begin{array}{llll}\text { wild-type } & 2 & 87 & 72\end{array}$

Total number of hatched eggs

$\begin{array}{lccc}\text { y1 } & 33 & 34 & 9 \\ \text { mi-2001 } & 27 & 39 & 0 \\ \text { zp4 } & 4 & 2 & 1 \\ \text { wild-type } & 1 & 32 & 54\end{array}$

645 Note: Fish were also held at $6^{\circ} \mathrm{C}$ but experienced $80-100 \%$ mortality within the first week so this 646 group was discontinued. 


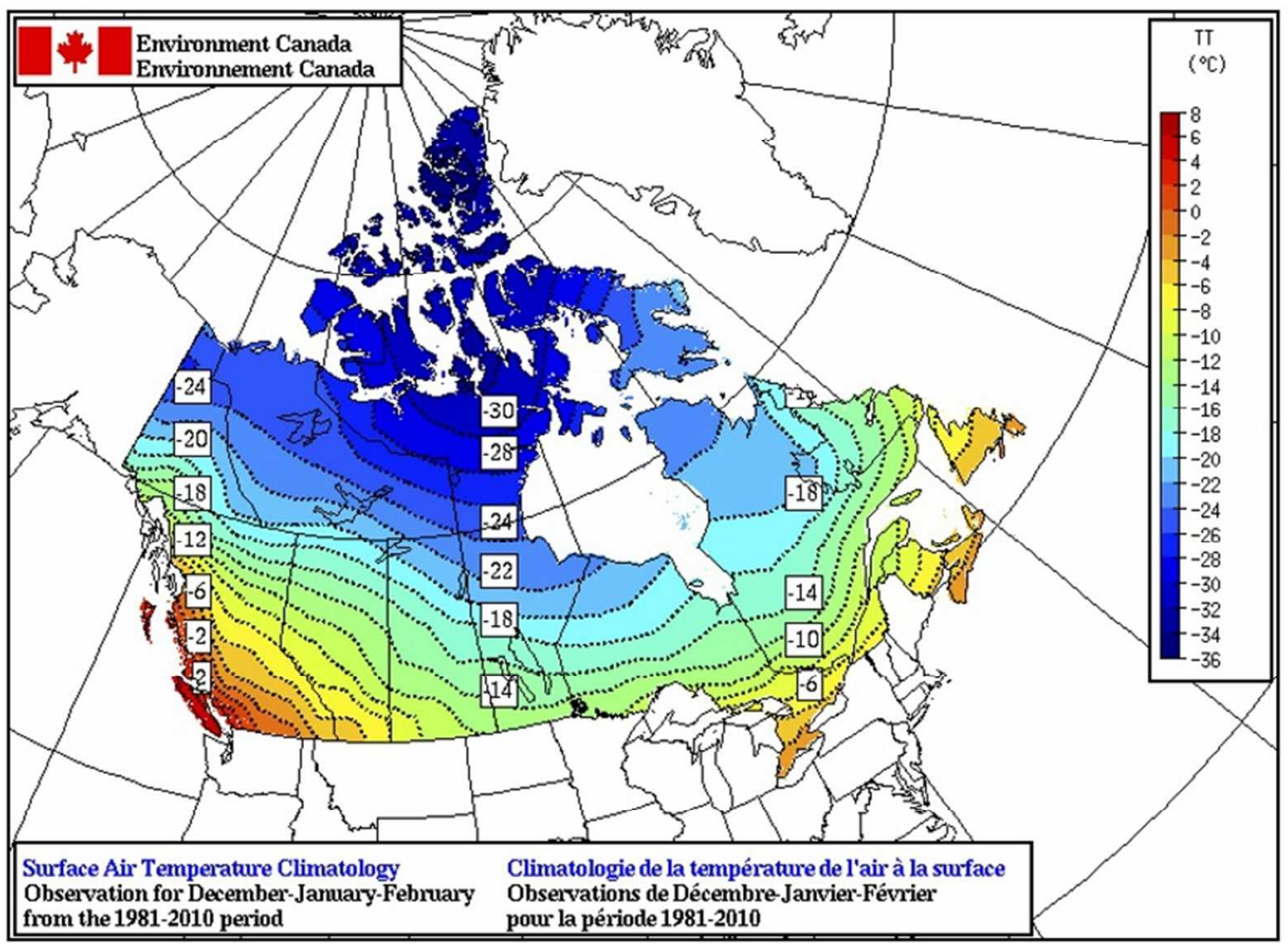

Figure 1: Surface air temperatures in Canada from December through February $71 \times 52 \mathrm{~mm}(300 \times 300$ DPI $)$ 


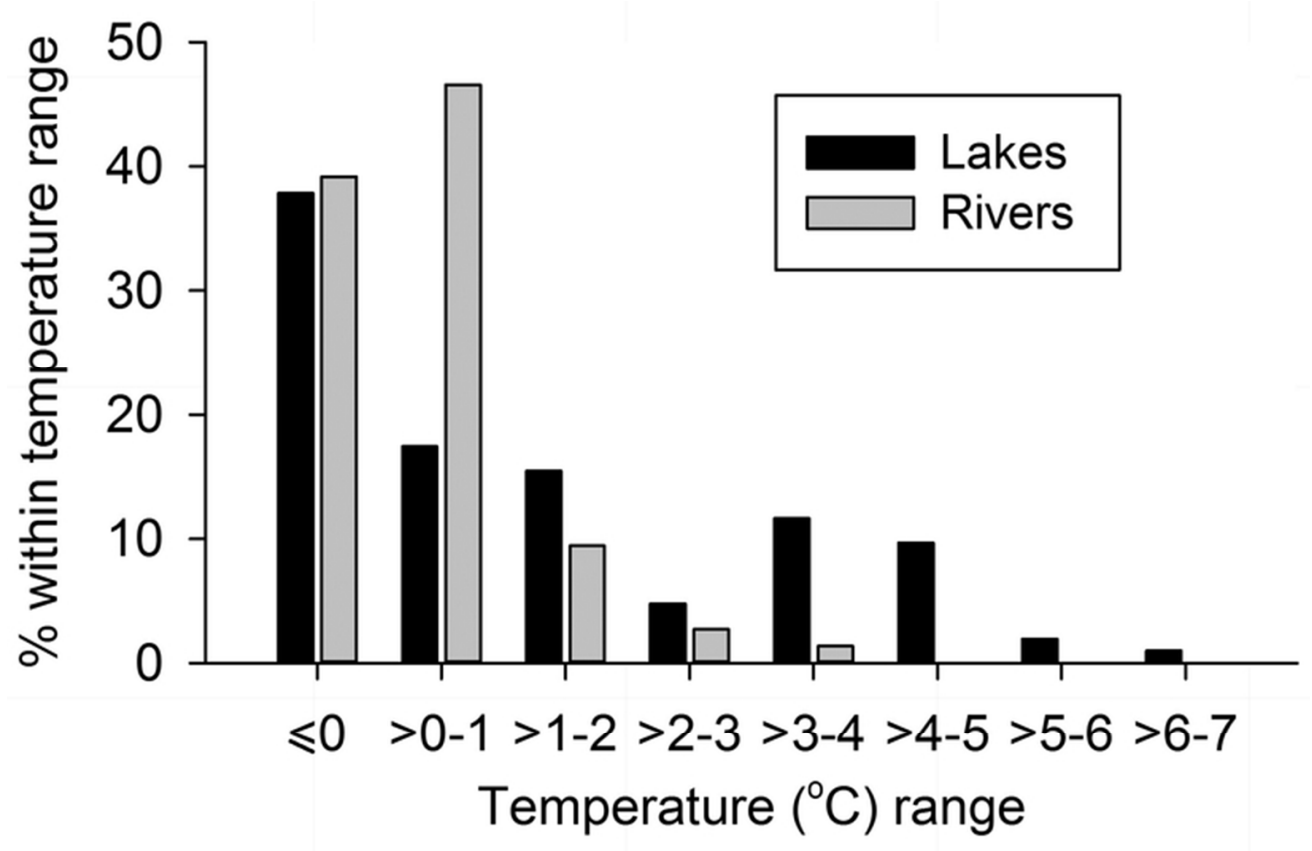

Figure 2: Distribution of minimum winter water temperatures in Canada $69 \times 45 \mathrm{~mm}(300 \times 300 \mathrm{DPI})$ 


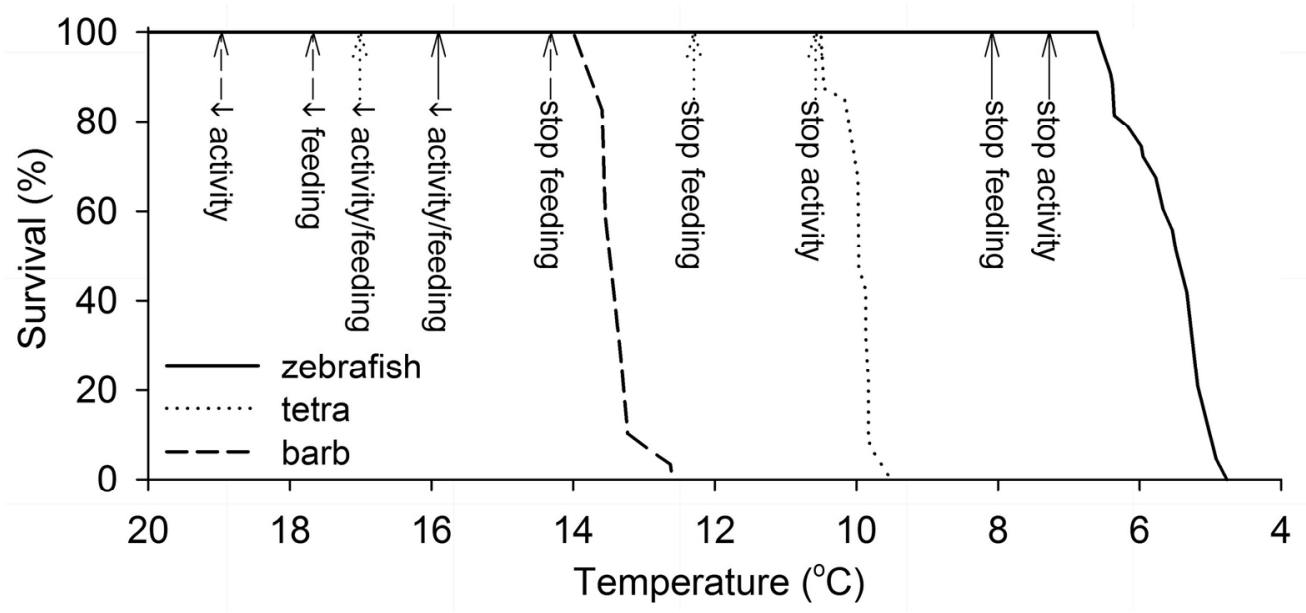

Figure 3: CLmin of aquarium fish

$170 \times 79 \mathrm{~mm}(300 \times 300 \mathrm{DPI})$ 


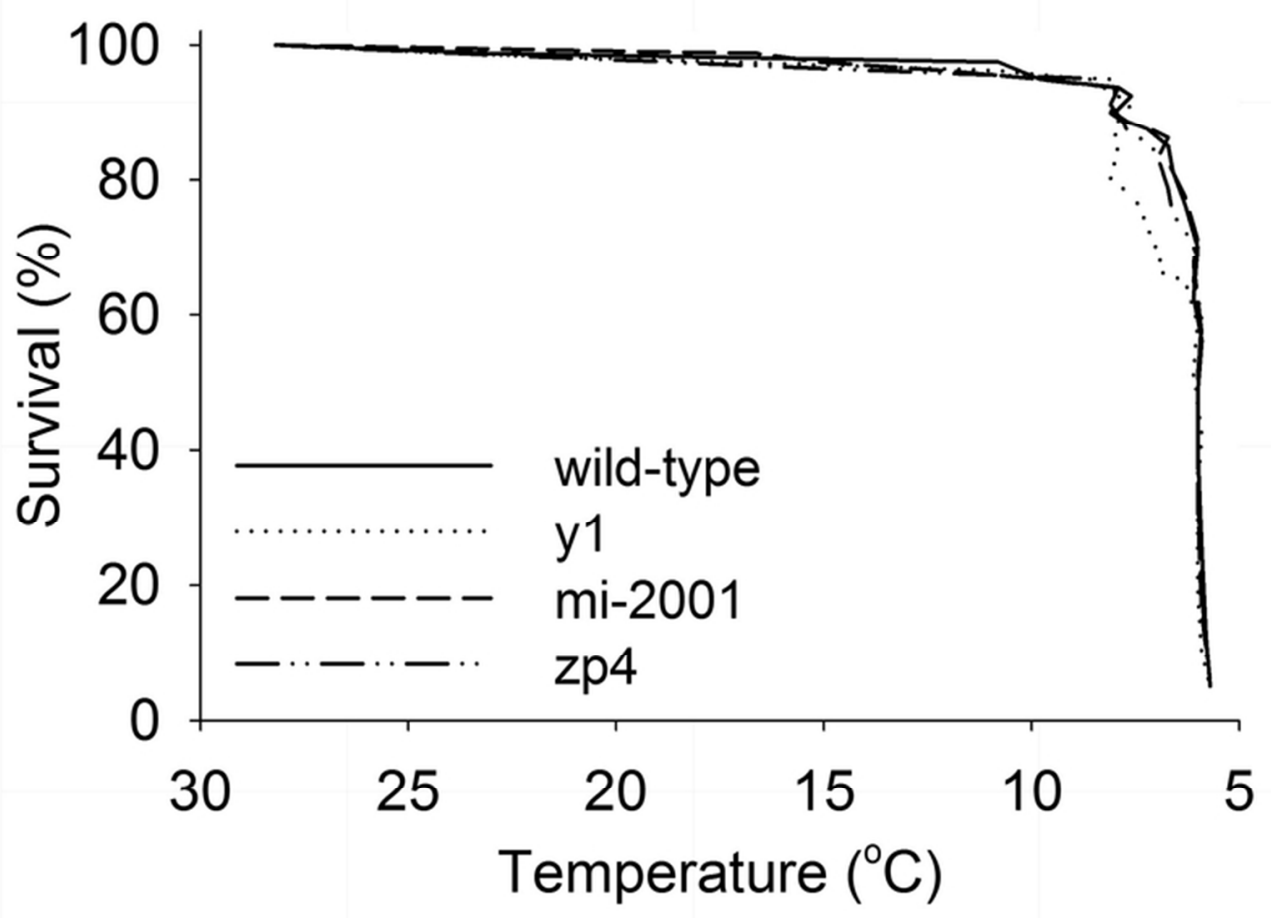

Figure 4: LT50 of zebrafish GFP lines $68 \times 48 \mathrm{~mm}(300 \times 300$ DPI $)$ 